Arch. Met. Geoph. Biokl., Ser. A, 19, 329-337 (1970)

(C) by Springer-Verlag 1970

Department of Environmental Sciences

University of Virginia, Charlottesville, Virginia, U.S.A.

\title{
A Study of Time Dependence During Serial Needle Ice Events
}

\section{Sam I. Outcalt}

With 2 Figures

Received March 31, 1970

Revised Manuscript Received April 23, 1970

\section{Summary}

Soil surface temperature, net radiation and soil heave data during a series of eleven consecutive needle ice growth-melt cycles at Vancouver, Canada, were studied using computer-graphic techniques. A method of analyzing the morphologic evolution of a needle growth using surface temperature and soil heave data is presented. Lastly, an atmospheric-geomorphic correlation matrix derived partially from the analysis of surface temperature-heave data is used to highlight the importance of afternoon evaporation in determining the course of an individual needle ice event within an event series.

\section{Zusammenfassung}

Über die zeitliche Entwicklung bei der Bildung von Eisnadeln

Bodentemperatur, Strahlungsbilanz und Bodenbewegungsdaten aus Vancouver, Kanada, werden für eine Serie von elf aufeinanderfolgenden Wachstums- und Schmelzzyklen von Eisnadeln graphisch wiedergegeben. Eine Methode zur Analyse der morphologischen Entwicklung des Nadelwachstums mit Hilfe von Bodentemperaturen und Bodenbewegungsdaten wird beschrieben. Schließlich wird eine Korrelationsmatrize zwischen atmosphärischen und geomorphologischen Daten teilweise aus den Daten der Bodentemperatur und Bodenbewegung abgeleitet und dazu benützt, die Bedeutung der Verdunstung am Nachmittag für den Verlauf der Nadelbildung innerhalb der beschriebenen Serie zu demonstrieren. 


\section{Introduction}

Needle ice is the product of ice segregation near the soil surface (Fig. 1). Ice segregation is the increase in the water (ice) volume fraction of a soil layer produced by the upward migration of soil water toward the freezing plane during diurnal frost events. Needle

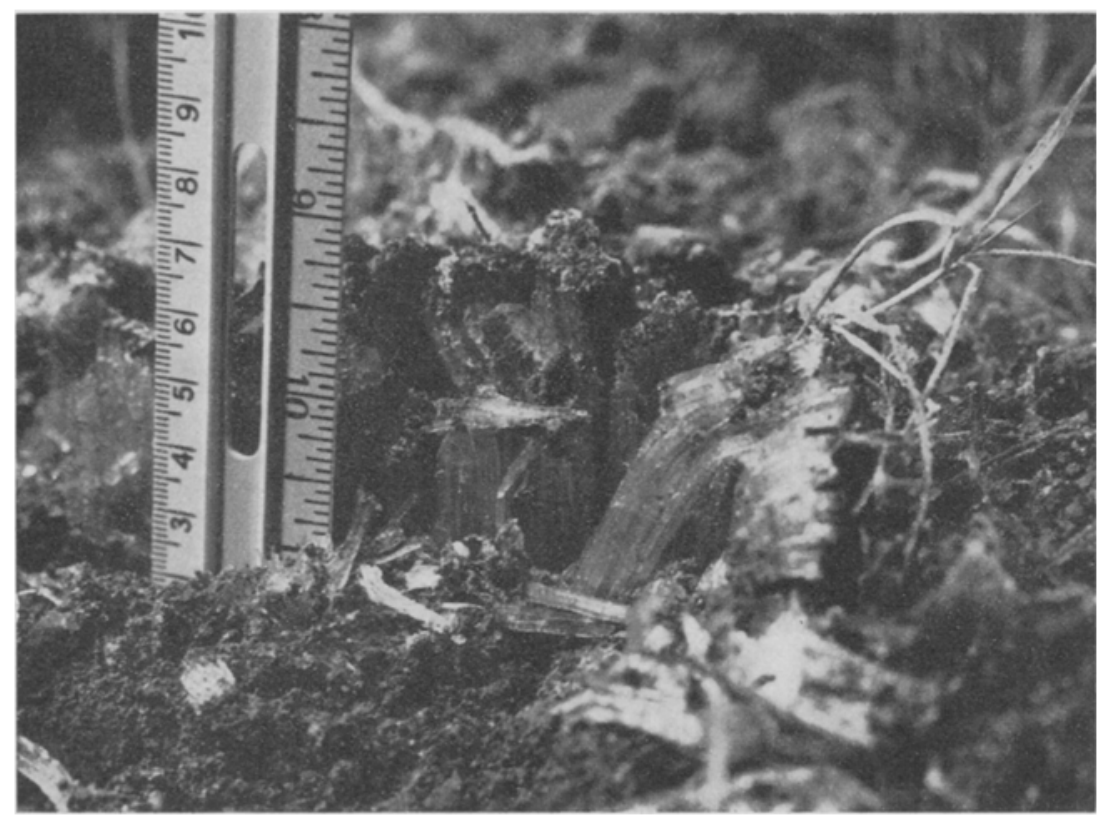

Fig. 1. Needle ice in a backyard garden, Vancouver. Note thin cap of "hard frozen" soil above the needles

ice growth and prediction is of considerable interest due to the plant damage which is often the product of a needle ice event [2].

The availability of soil water below and the soil heat flux above the freezing plane are the joint variables which determine if ice segregation (needle ice) or normal freezing (pore water frozen in situ) will occur during a diurnal ground frost event $[8,10,12]$. Thus, diurnal segregation will occur at a depth in medium textured soils (loams) where the soil water tension is below a critical value and the energy expended on fusion can be extracted by the maintenance of a sufficiently steep thermal gradient between the freezing plane and the soil surface $[8,11,12]$.

The normal climatological environment for cyclic nocturnal needle growth and daytime melting at Vancouver, Canada is the appearance of clear-cold-dry anticyclonic air over the area for extended 
periods during the cold portion of the year at times when the soil surface is unfrozen and wet during the day. The needle ice season at Vancouver runs from October through early March with high event frequencies at both the beginning and end of the period. The low frequency of mid-winter events is due to the soil being hard frozen for extended periods [7].

During the nocturnal growth of ice needles, the heat sinks for the growing needles are thermal radiation to a cold night sky, often with an equivalent radiant temperature as low as -20 to $-23^{\circ} \mathrm{C}$, and evaporation to the cold-dry overlying anticyclonic air, with near surface dew point temperatures well below the ice point [7]. Under these conditions, the relatively hot-wet soil surface produces the steep vapor pressure gradient necessary for evaporation and a strong net radiation deficit [4]. During periods of evaporation, the water content of the soil increases with depth placing the soil layer with a sufficiently high water content, low soil water tension, for the initiation of needle growth several millimeters below the surface. Thus, after ice nucleation there is a period of normal (in situ) freezing during which a cap of "hard frozen" soil is formed. This cap later rides atop the growing needles. To date, there has been only limited data available concerning the range and variance of stages in the natural needle ice growth sequence [5]. This paper will describe the methods used by the author to detect and analyze the stages in the diurnal needle ice growth-melting cycle using surface temperature and heave data.

\section{The Observations}

During an eleven day period starting at 1200 PST on 6 February 1968, serial diurnal needle ice growth-ablation (melt) events occurred in the surface layers of an uncropped sandy-loam field adjacent to the agrometeorological site maintained by the Department of Plant Sciences at the University of British Columbia. During this period, a continuous record of net radiation, soil surface temperature, soil heat flux and soil heave were obtained during the author's thesis research on needle ice growth at Vancouver (detailed information on instrumentation is available on request). The record was originally in the form of strip charts which were sampled at quarterhour intervals and punched onto computer data cards. The time span for each event ran from noon to noon as a complete growthablation cycle occurred in this interval.

During this event series, the weather was anticyclonic and each day appeared to be a duplicate of the preceeding day insofar as the 
diurnal regimes of net radiation, surface temperature and soil heat flux were concerned. In an attempt to formalize this notion, the author used the scheme of periodic regression and variance analysis developed by BLIss [1,3]. It was found that in the case of all four variables only the first two harmonics of an emperically fitted Fourier Series removed a significant $\left(F_{.99}\right)$ portion of the variance in the observed data. Further, only in the case of the soil heave record was there a statistically significant $\left(\mathrm{F}_{.95}\right)$ degree of variance between diurnal events (replicates). This variance in heave being mainly the result of great variability in the amplitude of the first harmonic from day to day. In short, total needle height varied to a statistically significant degree between events (replicates) although the growthablation sequence (phase) did not. Soil heat flux was not considered in the continued analysis due to the well recognized effects of water migration on the absolute output of the thermopile and variable relative depth during growth periods. Computer graphic plots of the other three variables during the eleven day event series were compiled. A sample plot is presented as Fig. 2. Having established the presence of a significant homogeneity among events as measured by the net radiation, surface temperature and soil heat flux regimes, the variability of needle growth and the sequence of events leading to growth would appear to be an interesting area for further investigation.

\section{The Needle Growth-ablation Sequence}

The first step in the analysis of the growth-ablation (melting) sequence is the recognition of a series of critical temporal events which can be used in the interpretation of the surface temperatureheave record to compare the course of needle ice events and provide the variable sets for event analysis. These events are as follows:

Nucleation: The surface temperature must decline well below the freezing point to the region of $-1^{0} \mathrm{C}$, the ice nucleation temperature. After the formation of ice nucleii near the surface, the temperature returns to the fusion temperature of the soil water [6].

The Onset of Heave: The soil begins to noticeably heave. Prior to this time heave is due to the $10 \%$ expansion of soil pore water on fusion. As the water volume percentage in the site soil prior to segregation is in the realm of $25 \%$, the heave is limited to the order of $0.25 \mathrm{~mm}$ for each $\mathrm{cm}$ of freezing plane descent [7]. At the time that heave begins, the freezing plane has descended to a level in the soil where the water content and flow environment are sufficient for the initiation and maintenance of the segregation process at the 
current heat withdrawal rate down the thermal gradient between the freezing plane and the subfreezing soil surface.

The Onset of Melting: Shortly after the sun rises, as the net radiation balance becomes positive, the surface temperature begins a slow climb to the ice point. Once the needles and soil cap are warmed to and isothermal at the ice point ablation (melting) begins. Ablation occurs both at the top, due to absorption of solar radiation, and at the base of the cap-needle mass, as the heat stored in the soil during the previous clear daylight period flows upward melting the bases of the isothermal needles. This event is recognized by the warming of the surface to the ice point and the nearly simultaneous descent of the heave probe as it begins a comparatively rapid trip toward its pre-heave elevation.

Completion of Ablation: The complete ablation and destruction of the needles is indicated by the return of the heave probe to its initial level. Continued studies at Charlottesville, Virginia indicate that if the three-dimensional geography of needle growth is hetrogeneous (spatially discontinuous, dirty needles) the soil structure is loosened, increasing the specific volume through increasing the relative pore volume. Under these conditions, the heave meter will not return to its initial elevation after ice melting is completed as the discontinuous voids produced by spatially hetrogeneous needle growth are structurally stable over diurnal cycles. This type of needle growth appears to have a greater effect in "loosening" soil structure than homogeneous needle growth [8].

It is possible to classify the time periods between these events as stages in the diurnal needle ice cycle of growth and ablation. This classification is as given in Table 1.

Table 1. Time-Stage Listing

\begin{tabular}{ll}
\hline Time period & Stage in cycle \\
\hline $\begin{array}{l}\text { Nucleation - } \\
\text { Onset of heave }\end{array}$ & $\begin{array}{l}\text { Normal freezing. Pore water frozen in situ. Cap } \\
\text { development. } \\
\text { Ice needles growing due to ice segregation. }\end{array}$ \\
$\begin{array}{l}\text { Onset of heave - } \\
\text { Onset of melting }\end{array}$ & $\begin{array}{l}\text { (a) Heave probe returns to initial elevation } \\
\text { Onset of melting }-\end{array}$ \\
$\begin{array}{l}\text { Ablation of a homogeneous clear needle growth. } \\
\text { probe completed }\end{array}$ & $\begin{array}{l}\text { (b) Heave probe returns to elevation above initial } \\
\text { elevation - Ablation of heterogeneous dirty needles. }\end{array}$ \\
$\begin{array}{l}\text { At the end of the ablation period the soil surface } \\
\text { probe completed }-\end{array}$ & $\begin{array}{l}\text { layers (upper } 2 \text { cm) are saturated above field capacity } \\
\text { due to meltwater. However, during the afternoon }\end{array}$ \\
Next nucleation & $\begin{array}{l}\text { hours this zone becomes desiccated due to the } \\
\text { infiltration and evaporation of meltwater. }\end{array}$
\end{tabular}


During the last stage of the cycle, the degree of desiccation is critical as the soil water content in the surface layers is the primary natural variable factor which determines both the thermal and water flow properties of the soil. The three parameters of volumetric soil water content, the soil thermal property (volumetric heat capacity $\times$ conductivity), and the unsaturated hydraulic conductivity are physically related. These parameters strongly interact through feedback loops which produce a "state of the soil surface system" which largely governs the slope of the surface temperature-time cooling curve, the morphology and the evolutionary development of frozen soil structure $[7,8]$.

If the time dependent stages of needle growth illustrated in Fig. 2 and interpreted using the information contained in Table 2 are incorporated into an atmospheric-geomorphic data matrix it is

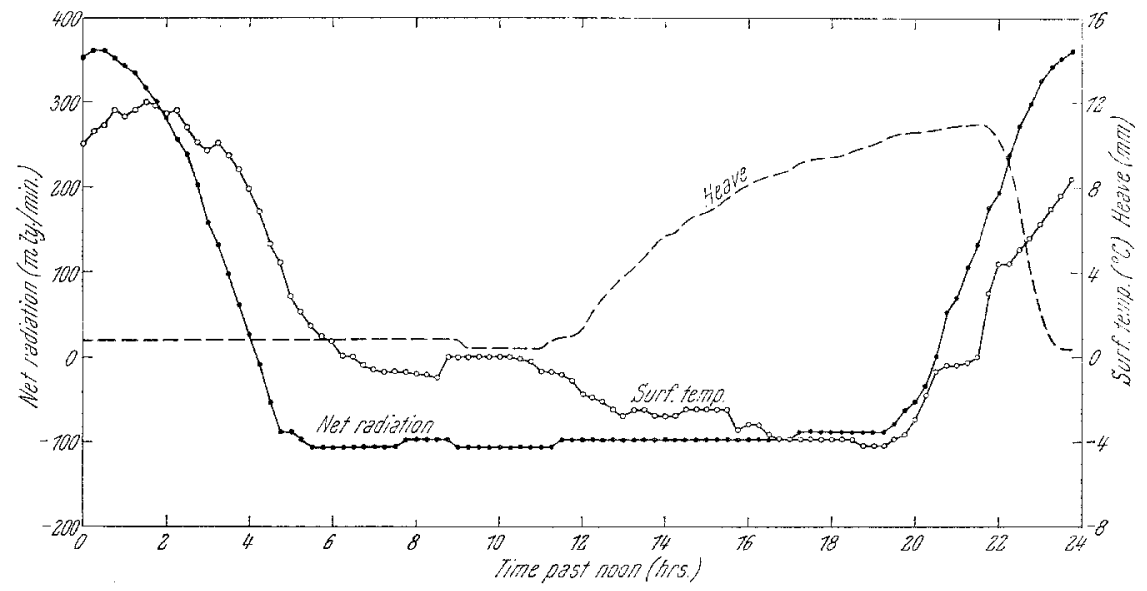

Fig. 2. A sample computer-graphic plot of net radiation, soil heave and soil surface temperature during one needle growth-ablation cycle beginning at 200 PST, 15 February 1968. Eleven of these plots were analyzed in this study

possible to gain some insight into the complex surface environmental system which governs both the rate of evolution and the morphology of ice needle growths. The following easily obtainable variables will be used:

$X_{1} \quad$ Nucleation Time (hrs. past noon [PST])

$X_{2} \quad$ Cap Growth Period (hrs.)

$X_{3}^{2} \quad$ Needle Growth Period (hrs.)

$X_{4} \quad$ Needle Height $(\mathrm{mm})$

$X_{5}^{4} \quad$ Max. Surface Temperature $\left({ }^{\circ} \mathrm{C}\right)$

$X_{6} \quad$ Max. Net Radiation Flux (ly/min)

$X_{7} \quad$ Time of Surface Temp. Max. (hrs. past noon)

$X_{8} \quad$ Time of Max. Radiation Flux (hrs. past noon) 
The resultant data matrix is as given in Table 2 .

Table 2. The Data Matrix

\begin{tabular}{crrrrrrrr}
\hline Day & $X_{1}$ & $X_{2}$ & $X_{3}$ & $X_{4}$ & $X_{5}$ & $X_{6}$ & $X_{7}$ & $X_{8}$ \\
\hline 1 & 11.0 & 1.0 & 7.6 & 9.9 & 10.9 & .350 & 1.2 & 0.5 \\
2 & 9.0 & 2.3 & 8.5 & 10.4 & 12.0 & .340 & 1.7 & 0.4 \\
3 & 10.5 & 2.2 & 8.2 & 9.6 & 13.4 & .340 & 1.9 & 0.0 \\
4 & 11.2 & 3.0 & 5.3 & 4.6 & 13.0 & .345 & 1.6 & 0.8 \\
5 & 12.0 & 3.0 & 5.6 & 7.6 & 13.4 & .350 & 2.0 & 0.4 \\
6 & 9.7 & 3.0 & 7.5 & 10.1 & 13.0 & .350 & 2.0 & 0.4 \\
7 & 11.0 & 3.8 & 4.7 & 7.5 & 13.6 & .370 & 1.4 & 0.2 \\
8 & 12.5 & 3.3 & 4.5 & 6.8 & 13.0 & .350 & 2.2 & 1.1 \\
9 & 8.5 & 2.3 & 10.0 & 10.1 & 12.0 & .360 & 1.5 & 0.3 \\
10 & 6.7 & 3.5 & 9.6 & 12.0 & 12.7 & .370 & 2.0 & 0.1 \\
11 & 7.3 & 4.0 & 8.4 & 10.6 & 13.5 & .375 & 0.3 & 1.1 \\
Means.. & 9.9 & 2.9 & 7.3 & 9.0 & 12.8 & .355 & 1.6 & 0.5 \\
Std. Dev. & 1.8 & 0.8 & 1.9 & 2.0 & 0.8 & .014 & 0.5 & 0.4
\end{tabular}

From these values the following correlation matrix Table 3 was calculated.

Table 3. Correlation Matrix

\begin{tabular}{lcccccccc}
\hline & $X_{1}$ & $X_{2}$ & $X_{3}$ & $X_{4}$ & $X_{5}$ & $X_{6}$ & $X_{7}$ & $X_{8}$ \\
\hline$X_{1}$ & 1.00 & -.21 & $-.84^{* *}$ & $-.78^{* *}$ & +.10 & -.55 & +.28 & +.08 \\
$X_{2}$ & & 1.00 & -.29 & -.15 & +.81 & $+.63^{*}$ & -.13 & +.26 \\
$X_{3}$ & & & 1.00 & $+.86^{* * *}$ & -.41 & +.16 & -.13 & +.30 \\
$X_{4}$ & & & 1.00 & -.32 & +.31 & -.12 & -.32 \\
$X_{5}$ & & & & 1.00 & +.25 & -.02 & +.02 \\
$X_{6}$ & & & & & 1.00 & -.50 & +.12 \\
$X_{7}$ & & & & & & 1.00 & -.32 \\
$X_{8}$ & & & & & & 1.00 \\
$*$ Significant at $F_{.05}[9]$. & & & & & & \\
$*$ Significant at $F_{.01}$. & & & & & &
\end{tabular}

Diagramatically, the first set of significant correlations are:

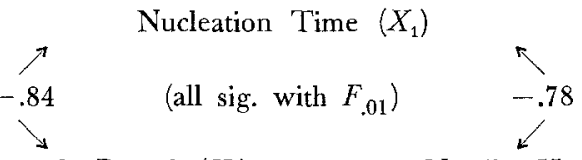

Needle Growth Period $\left(X_{3}\right) \neg+.86 \nearrow^{\text {Needle Height }\left(X_{4}\right)}$

Thus, simply stated, the earlier the time of nucleation the greater the needle height and the longer growth period. Also, the height of the needles increases with the length of the growth period. This result is hardly unexpected as the total potential growth period is finite being limited to the hours of darkness. 
However, at a slightly reduced level of significance, there are two pairs of less strongly correlated variables:

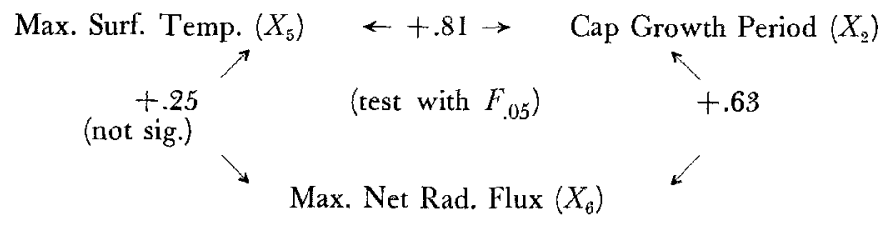

Maximum values of both surface temperature and net radiation are correlated with the duration of cap growth whereas there is no significant correlation between net radiation and temperature. As both net radiation and temperature are physically related to high potential evaporation from a wet surface, this result strongly suggests that the degree of evaporation desiccation achieved between ablation and nucleation in the afternoon and early evening hours determines the gross morphology of diurnally frozen soil by controlling the cap depth and spatial homogeneity of the segregation process.

\section{Conclusion}

Useful data concerning the course of needle ice growth can be gained from a study of the surface temperature-heave record. The analysis of serial events indicates that variable evaporation-infiltration desiccation of the upper soil layers during the afternoon and early evening hours is a mechanism which produces significant variations in both the morphologic and time dependent characteristics of serial ice needle growth.

\section{Acknowledgements}

The computer graphic research was carried out using funds provided by the Office of Sponsored Programs of the University of Virginia as a National Science Foundation Institutional Sub-Grant (70-290 L-A) for research on Weather and Frozen Soil Structures. The author is indebted to Professor J. Ross Mackay of the University of British Columbia for introducing him to "ice needles" and guiding his thesis research on this topic which provides a fascinating link between geomorphology and meteorology. Funds for field data collection and analysis were provided by the University of British Columbia and the National Research Council of Canada.

\section{References}

1. Buiss, C. I.: Periodic Regression in Biology and Climatology. Bull. 615, Conn. Agricultural Exp. Sta., New Haven, 55 pp. (1958).

2. Brink, V. C., J. R. Mackay, S. Freyman, and D. G. Pearce: Needle Ice and Seedling Establishment in Southwestern British Columbia. Can. Jour. of Plant Sci. 47, 135-139 (1967). 
3. Dixon, W. J.: Biomedical Computer Programs. U. of Calif. Press, Berkeley and Los Angeles (1968).

4. Fujita, M., el al:: Shimobashira no Kenkyu (Investigation of Frost Needles). Tokyo: Jiyugakuen, Translation at U.S. Army Cold Regions Research and Engineering Labs, Hanover, N. H. (1937).

5. Furada, H.: Ice Columns in Soil. J. Coll. Agric., Tokyo Imperial XIII (5), 453-481 (1936) (Translation JMS-3, CRREL).

6. Jumikis, A. R.: Thermal Soil Mechanics. New Brunswick, N. J.: Rutgers University Press, 267 pp., 1966.

7. Outcalt, S. I.: A Study of Needle Ice Events at Vancouver, Canada. Dissertation, University of British Columbia, Vancouver, 1970.

8. Outcalt S. I.: Weather and Diurnal Frozen Soil Structure at Charlottesville, Virginia. Water Resources Research 5, 1377-1381 (1969).

9. Panofsky, H. A., and G. W. Brier: Some Applications of Statistics to Meteorology. Penn. State University Press, 224 pp., 1963.

10. Penner, E.: The Importance of Freezing Rate in Frost Action in Soils. Proc. Amer. Soc. Testing Materials 60, 1151-1165 (1960).

11. Takagi, S.: Principles of Frost Heaving. Research Report 140, U.S. Army Cold Regions Research and Engineering Laboratory, Hanover, N. H., 1965.

12. Williams, P. J.: Properties and Behavior of Freezing Soils. 119 pp. Norges Gestek Inst. Publ. No. 72, 1968.

Author's address: Dr. SAM I. OUtCalt, Department of Geography, University of Michigan, Ann Arbor, MI 48104, U. S. A. 